\title{
Anaemia and associated factors among under-fives and their mothers in Bushenyi district, Western Uganda
}

\author{
Joyce K Kikafunda*, Fred B Lukwago and Florence Turyashemererwa \\ Department of Food Science and Technology, Makerere University, PO Box 7062, Kampala, Uganda
}

Submitted 29 January 2008: Accepted 19 January 2009: First published online 6 April 2009

\begin{abstract}
Objective: To determine the prevalence of anaemia and associated factors among under-fives and their mothers in a rural area of Western Uganda.

Design: A cross-sectional investigation using both qualitative and quantitative methods of data collection. Stratified multistage sampling methods were used to select the study sample. A haemoglobinometer was used to assess $\mathrm{Hb}$ levels in the blood.

Setting: A rural district in Western Uganda.

Subjects: Children aged 6-59 months and their mothers aged 15-49 years.

Results: The overall prevalence of Fe-deficiency anaemia among children and their mothers was $26 \cdot 2 \%$ and $17 \cdot 9 \%$, respectively. There was a significant correlation ( $r=0.5, P=0 \cdot 008$ ) between the Hb levels of the mothers and their children. Place of birth, age of the child, factors related to complementary foods, and formal education and nutrition knowledge of the mother were major factors that were significantly associated $(r=0 \cdot 05, P=0.05)$ with low Hb levels among the children. The most important factors that were associated with low Hb levels of the mothers were their formal education, nutrition knowledge and health status.

Conclusions: Fe-deficiency anaemia was found to be a major problem in this cohort of children and their mothers. Dietary factors and sociodemographic factors were the major factors associated with high levels of anaemia among the children and their mothers. It is therefore recommended that rural mothers should be sensitized on best practices for prevention of anaemia among both women and children.
\end{abstract}

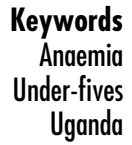

Uganda
Malnutrition remains a global challenge in developing countries, especially among young children and women of reproductive age (15-49 years). Malnourished women tend to deliver premature or underweight babies who are more likely to die or suffer from suboptimal growth and development ${ }^{(1)}$. Thus, undernutrition and ill health are passed on from generation to generation. Morbidity and mortality are highest among those most severely malnourished. However, mildly or moderately underweight individuals experience the greatest total burden of disease $\mathrm{e}^{(2)}$.

Micronutrient deficiencies are the most common nutritional disorders in the world. These include vitamin A deficiency, iodine deficiency disorders and Fe-deficiency anaemia, the latter of which is the greatest problem $^{(3,4)}$. Globally, over 3.5 billion people, more than half the world's population, are affected by Fe deficiency. Rates of Fe deficiency in developing countries are staggering ( $44 \%$ of women, $42 \%$ of preschoolers, $53 \%$ of school-aged children and $33 \%$ of men), with Asia and Africa having the highest prevalences ${ }^{(5)}$.

As a major component of $\mathrm{Hb}, \mathrm{Fe}$ is essential for the binding and transport of oxygen, as well as for the regulation of cell growth and differentiation ${ }^{(6)}$. Fe deficiency is the primary cause of anaemia, although vitamin A deficiency and folate deficiency $^{(7)}$, malaria and hookworm infestations ${ }^{(8)}$ and HIV/AIDS ${ }^{(9)}$ also result in anaemia. The major causes of anaemia in children in developing countries are mainly low bioavailability of Fe from plant-based diets resulting in inadequate dietary intakes of $\mathrm{Fe}$ and limited use of Fe-fortified infant foods and cereals ${ }^{(10)}$. Fe deficiency in children results in neurological impairment and growth and developmental retardation, which may not be fully reversible ${ }^{(11)}$.

In Uganda, $64 \%$ of children $<5$ years of age and $30 \%$ of women of reproductive age (15-49 years) had Fe-deficiency anaemia in 2000-1 ${ }^{(12)}$. Findings of the most recent demographic and health survey (2006) show that the levels of anaemia in children and mothers in Uganda have actually gone up, with $73 \%$ of children aged 6-59 months and $49 \%$ of women aged $15-49$ years (childbearing age) being anaemic ${ }^{(13)}$. A postpartum anaemia study showed a high prevalence $(65 \%)$ of anaemia among women in Tororo district, Eastern Uganda ${ }^{(14)}$. It is estimated that up to $30 \%$ of maternal deaths are attributable to anaemia ${ }^{(15)}$. 
A burden of disease study carried out by the Ministry of Health in several districts of Uganda ranked anaemia among the top ten leading causes of morbidity and mortality, responsible for $2 \cdot 3 \%$ of the burden of disease ${ }^{(16)}$.

Fe deficiency is known to decrease immune function, but some investigators have also hypothesized that Fe supplementation increases infectious disease ${ }^{(17)}$. Indeed, some controversy exists concerning Fe-deficiency anaemia in that it does not appear to contribute to growth faltering ${ }^{(18)}$. However, Stoltzfus et $a l^{(19)}$ found that Fe-deficiency anaemia was an underlying factor in 841000 deaths per year resulting from maternal and perinatal causes, and it directly caused the deaths of 134000 young children annually.

The present study was conducted to establish the prevalence of anaemia among the vulnerable groups of children and mothers and to determine whether there is a relationship between the $\mathrm{Hb}$ levels of the mothers and their children. In addition, the study sought to establish the factors associated with anaemia in this cohort of children and their mothers in a rural district in Western Uganda.

\section{Methods}

\section{Study design and sampling procedures}

The study employed a cross-sectional design using both qualitative and quantitative methods of data collection. Multistage sampling methods were used to select the study sub-counties, parishes and villages. Once a village was selected, all households with children $<5$ years of age had an equal chance of participating in the study. Stratified random sampling, with the help of local leaders, was used to select households with children $<5$ years of age.

\section{Study sample}

A sample of 104 subjects was recruited, of whom fifty-two were children $<5$ years old while fifty-two were the children's mothers within the age range of 15-49 years.

\section{Questionnaire validation and administration}

A questionnaire was developed based on that used by the Uganda Demographic Health Survey ${ }^{(12)}$ for a similar study and was validated by the 'jury' method ${ }^{(20)}$. The pre-tested questionnaire was used to collect data on socio-economic and demographic characteristics, as well as maternal nutritional knowledge about enriching the child's food and feeding habits. Maternal nutritional knowledge was determined using simple 'yes' or 'no' questions. The questionnaire was administered to the mothers in their own home settings (households).

\section{Fe status assessment}

Retractable disposable cuvettes (High Chem Uganda Limited, Kampala, Uganda) were used to draw blood samples and then inserted into a HemoCue ${ }^{\circledR}$ haemoglobinometer (HemoCue AB, Ångelholm, Sweden). The Hb assessment was done in the field at local health centres by a team of trained health personnel. The Hb levels in the blood were displayed on a digital register on the HemoCue and recorded. Cut-offs for anaemia, classified as severe, moderate and mild according to the WHO/United Nations University/UNICEF (2001) criteria, were used ${ }^{(21)}$.

\section{Data analysis}

Data were entered and analysed using the SPSS version 12 statistical software package (SPSS Inc., Chicago, IL, USA) with statistical significance set at a $P$ value of $\leq 0.05$. Associations between variables were determined using Pearson's correlations, and $\chi^{2}$ tests and $t$ tests to determine the relationships between variables.

\section{Etbical clearance}

Ethical clearance was given by Uganda National Council of Science and Technology. Before the study was conducted, the objectives and procedures were explained to the intended subjects who gave their informed consent.

\section{Results}

\section{Sociodemographic characteristics of the study population}

Table 1 summarizes the sociodemographic characteristics of the studied children, including age, sex, place of birth and factors related to complementary foods. A large proportion $(44.4 \%)$ of the children were in the $13-24$ months age range. More than half of the children $(56.9 \%)$ were born at home. A large majority of the children (88.3\%) were introduced to complementary foods too early (at age

Table 1 Sociodemographic characteristics of the under-fives ( $n$ 52), Bushenyi district, rural Western Uganda

\begin{tabular}{lc}
\hline Characteristic & $\begin{array}{c}\text { Distribution } \\
(\%)\end{array}$ \\
\hline Age of child (months) & \\
$6-12$ & $11 \cdot 3$ \\
$13-24$ & $44 \cdot 4$ \\
$25-36$ & $37 \cdot 1$ \\
$37-59$ & $11 \cdot 3$ \\
Sex & \\
Male & $42 \cdot 9$ \\
Female & $57 \cdot 1$ \\
Place of birth & \\
Home & $56 \cdot 9$ \\
Community birth attendant & $15 \cdot 7$ \\
Health centre & $27 \cdot 5$ \\
Age (months) at introduction of complementary & \\
foods & \\
>6 & $88 \cdot 3$ \\
6-9 & $10 \cdot 0$ \\
9-12 & $1 \cdot 7$ \\
First complementary foods & $3 \cdot 4$ \\
Animal products, e.g. milk & $96 \cdot 6$ \\
Staples, e.g. maize and millet porridge & \\
Separate food prepared for the child & $20 \cdot 4$ \\
Yes & $79 \cdot 7$ \\
No & \\
\hline &
\end{tabular}


4 months and below), before the recommended age of 6 months. An even larger majority $(96 \cdot 6 \%)$ of the children were weaned on to starchy staples such as cereal porridges. The majority of the children $(79 \cdot 7 \%)$ who were $>6$ months of age had no specific meals prepared for them and were therefore sharing family meals.

Table 2 summarizes the sociodemographic characteristics of the studied mothers, which included age, physiological

Table 2 Sociodemographic characteristics of the mothers ( $n 52)$, Bushenyi district, rural Western Uganda

\begin{tabular}{|c|c|}
\hline Characteristic & Distribution (\%) \\
\hline \multicolumn{2}{|l|}{ Maternal age (years) } \\
\hline $15-24$ & $33 \cdot 3$ \\
\hline $25-29$ & $36 \cdot 5$ \\
\hline $30-34$ & $14 \cdot 3$ \\
\hline$>35$ & $15 \cdot 9$ \\
\hline \multicolumn{2}{|l|}{ Age at first parity (years) } \\
\hline$<18$ & $31 \cdot 0$ \\
\hline $19-24$ & $67 \cdot 2$ \\
\hline $25-29$ & $1 \cdot 7$ \\
\hline \multicolumn{2}{|l|}{ Physiological status } \\
\hline Pregnant & $17 \cdot 5$ \\
\hline Lactating & $66 \cdot 6$ \\
\hline Non-lactating/non-pregnant & $15 \cdot 9$ \\
\hline \multicolumn{2}{|l|}{ Maternal education } \\
\hline None & $51 \cdot 7$ \\
\hline Primary & $22 \cdot 4$ \\
\hline Secondary & $12 \cdot 1$ \\
\hline Tertiary & $10 \cdot 3$ \\
\hline \multicolumn{2}{|c|}{ Knowledge of enriching child's food } \\
\hline Yes & $18 \cdot 9$ \\
\hline No & $81 \cdot 1$ \\
\hline \multicolumn{2}{|l|}{ Source of knowledge about Fe } \\
\hline Health unit & $71 \cdot 0$ \\
\hline Health worker & $22 \cdot 6$ \\
\hline Friend/relative & $6 \cdot 5$ \\
\hline \multicolumn{2}{|l|}{ Diseases and infections } \\
\hline Cough & $45 \cdot 3$ \\
\hline Malaria & $20 \cdot 8$ \\
\hline Worms & $7 \cdot 5$ \\
\hline Headache & $7 \cdot 5$ \\
\hline Flu/cold & $5 \cdot 7$ \\
\hline Diarrhoea & 1.9 \\
\hline Fever & $1 \cdot 9$ \\
\hline \multicolumn{2}{|l|}{ Distance to health facility (h) } \\
\hline $0-0 \cdot 25$ & $17 \cdot 2$ \\
\hline $0.25-0.5$ & $24 \cdot 1$ \\
\hline $0 \cdot 5-1$ & $24 \cdot 1$ \\
\hline $1-2$ & $27 \cdot 6$ \\
\hline$>2$ & 6.9 \\
\hline
\end{tabular}

status, maternal education and factors related to health. More than a third of the mothers (36.5\%) were in the age range of 25-29 years. About a third of the mothers $(31 \cdot 0 \%)$ had their first parity while still very young $(<18$ years), while more than two-thirds $(67 \cdot 2 \%)$ had their first parity between 19 and 24 years. Two-thirds of the studied mothers $(66 \cdot 6 \%)$ were lactating while $17 \cdot 5 \%$ were pregnant. Almost half of the mothers $(49 \cdot 2 \%)$ had never attended any formal education, with $81 \cdot 1 \%$ not having any knowledge about enriching children's food (enriching a child's food entails adding energy- and nutrientdense foods to a child's food to nutritionally enrich it). The health unit was the major source of knowledge on Fe for the mothers, while acute respiratory infections were the main health problems among the study population. More than a quarter of the mothers (27.6\%) walked for $1-2 \mathrm{~h}$ to reach the nearest health facility.

\section{Prevalence of anaemia among the study population}

The anaemia prevalence among the study population is shown in Table 3. The overall prevalence of anaemia among children and their mothers was $26 \cdot 2 \%$ and $17 \cdot 9 \%$, respectively. Lactating mothers were more anaemic in all the three categories of Fe-deficiency anaemia compared with pregnant and non-lactating/non-pregnant mothers.

\section{Factors associated with anaemia among under-fives}

In order to determine the factors associated with anaemia within the study population, all anaemia categories were merged to form two groups: anaemic and non-anaemic (normal). The factors associated with anaemia status of the children are presented in Table 4 . The age of the child was significantly associated $(P=0 \cdot 019)$ with the child's anaemia status, with infants and children aged $1-3$ years being more anaemic than their younger and older counterparts. Males were significantly $(P=0 \cdot 005)$ more anaemic than females. The place of delivery was significantly $(P=0.035)$ associated with anaemia prevalence among the children, those born at home having a higher proportion of anaemia compared with those born at a health facility.

Table 3 Distribution of $\mathrm{Hb}(\mathrm{g} / \mathrm{dl})$ among the study subjects, Bushenyi district, rural Western Uganda

\begin{tabular}{|c|c|c|c|c|}
\hline Population & $\begin{array}{c}\text { Normal } \\
(>11 \mathrm{~g} / \mathrm{dl})\end{array}$ & $\begin{array}{c}\text { Mildly anaemic } \\
(10-10.9 \mathrm{~g} / \mathrm{dl})\end{array}$ & $\begin{array}{c}\text { Moderately anaemic } \\
(7-9.9 \mathrm{~g} / \mathrm{dl})\end{array}$ & $\begin{array}{c}\text { Severely anaemic } \\
(<7 \mathrm{~g} / \mathrm{dl})\end{array}$ \\
\hline \multicolumn{5}{|l|}{ Children ( $n$ 52) } \\
\hline Male & $73 \cdot 0$ & $9 \cdot 5$ & $17 \cdot 5$ & 0.0 \\
\hline Female & $74 \cdot 6$ & $11 \cdot 1$ & $11 \cdot 1$ & $3 \cdot 2$ \\
\hline Total & $73 \cdot 8$ & $10 \cdot 3$ & $14 \cdot 3$ & $1 \cdot 6$ \\
\hline \multicolumn{5}{|l|}{ Mothers ( $n$ 52) } \\
\hline Pregnant & $95 \cdot 5$ & $3 \cdot 2$ & $0 \cdot 0$ & $1 \cdot 3$ \\
\hline Lactating & $66 \cdot 6$ & $14 \cdot 3$ & $27 \cdot 0$ & $3 \cdot 2$ \\
\hline $\begin{array}{l}\text { Non-lactating/ } \\
\text { non-pregnant }\end{array}$ & $95 \cdot 2$ & $3 \cdot 2$ & $1 \cdot 6$ & 0.0 \\
\hline Total & $85 \cdot 6$ & $6 \cdot 9$ & $9 \cdot 5$ & 1.5 \\
\hline
\end{tabular}


Table 4 Factors associated with the prevalence of anaemia $(\mathrm{Hb}<11 \mathrm{~g} / \mathrm{dl})$ among the under-fives ( $n 52)$, Bushenyi district, rural Western Uganda

\begin{tabular}{|c|c|c|}
\hline Factor & $\begin{array}{c}\text { Anaemia } \\
\text { prevalence (\%) }\end{array}$ & $P$ value \\
\hline \multicolumn{3}{|l|}{ Age of child (months) } \\
\hline $6-12$ & $9 \cdot 7$ & 0.019 \\
\hline $13-24$ & $22 \cdot 6$ & \\
\hline $25-36$ & $16 \cdot 2$ & \\
\hline $37-59$ & $3 \cdot 2$ & \\
\hline \multicolumn{3}{|l|}{ Sex } \\
\hline Male & $27 \cdot 0$ & 0.005 \\
\hline Female & $25 \cdot 4$ & \\
\hline \multicolumn{3}{|l|}{ Place of birth } \\
\hline Home & $23 \cdot 5$ & 0.035 \\
\hline Community birth attendant & $11 \cdot 8$ & \\
\hline Health centre & $13 \cdot 7$ & \\
\hline \multicolumn{3}{|l|}{ Maternal education } \\
\hline None & $24 \cdot 8$ & 0.000 \\
\hline Primary & $62 \cdot 2$ & \\
\hline Secondary & $2 \cdot 4$ & \\
\hline Tertiary & $4 \cdot 0$ & \\
\hline \multicolumn{3}{|l|}{$\begin{array}{l}\text { Age (months) at introduction of } \\
\text { complementary foods }\end{array}$} \\
\hline$<6$ & $41 \cdot 6$ & 0.001 \\
\hline$>6$ & $5 \cdot 0$ & \\
\hline \multicolumn{3}{|l|}{ First complementary foods } \\
\hline Animal products, e.g. milk & $13 \cdot 6$ & 0.04 \\
\hline Staples, e.g. maize and millet porridge & $37 \cdot 4$ & \\
\hline \multicolumn{3}{|l|}{$\begin{array}{l}\text { Mother's knowledge of enriching child's } \\
\text { food }\end{array}$} \\
\hline Yes & $17 \cdot 0$ & 0.005 \\
\hline No & $35 \cdot 8$ & \\
\hline \multicolumn{3}{|l|}{ Special food prepared for child } \\
\hline Yes & $16 \cdot 7$ & 0.028 \\
\hline No & $37 \cdot 1$ & \\
\hline \multicolumn{3}{|l|}{ Mother's source of knowledge about Fe } \\
\hline Health unit & $9 \cdot 7$ & 0.07 \\
\hline Health worker & $6 \cdot 5$ & \\
\hline Friend/relative & $3 \cdot 2$ & \\
\hline
\end{tabular}

Maternal education was significantly $(P=0 \cdot 000)$ associated with the children's anaemia status, with mothers with no formal education and those with only primary education having more children with anaemia than mothers with secondary and tertiary education. The age of introduction of complementary foods was significantly $(P=0 \cdot 001)$ associated with the children's anaemia status, those who were introduced to complementary foods before 6 months having higher rates of anaemia (41.6\%) compared with those who started complementary foods after 6 months $(5 \cdot 0 \%)$.

The poor access to information about enriching a child's food also contributed significantly to anaemia among the children. Mothers who had no knowledge about enriching children's food (e.g. the use of triple mixture ingredients from locally available foods) had significantly $(P=0 \cdot 005)$ higher proportions of anaemic children compared with mothers who were knowledgeable in this respect. Children who were fed food prepared specially for them (i.e. enriched food) had significantly $(P=0 \cdot 028)$ lower rates of anaemia than children who were usually fed family food with no special foods prepared for them. Those children
Table 5 Factors associated with the prevalence of anaemia $(\mathrm{Hb}<11 \mathrm{~g} / \mathrm{dl})$ among the mothers ( $n 52)$, Bushenyi district, rural Western Uganda

\begin{tabular}{|c|c|c|}
\hline Factor & $\begin{array}{c}\text { Anaemia } \\
\text { prevalence (\%) }\end{array}$ & $P$ value \\
\hline \multicolumn{3}{|l|}{ Diseases and infections } \\
\hline $\begin{array}{l}\text { Acute respiratory infections } \\
\text { (cough, cold) }\end{array}$ & $28 \cdot 3$ & 0.000 \\
\hline Worms & $23 \cdot 5$ & \\
\hline Malaria & $11 \cdot 7$ & \\
\hline Headache & $5 \cdot 7$ & \\
\hline Fever & $1 \cdot 9$ & \\
\hline Diarrhoea & $8 \cdot 9$ & \\
\hline \multicolumn{3}{|l|}{ Maternal age (years) } \\
\hline $15-24$ & $9 \cdot 5$ & 0.066 \\
\hline $25-29$ & $8 \cdot 0$ & \\
\hline $30-34$ & $3 \cdot 2$ & \\
\hline$>35$ & $1 \cdot 6$ & \\
\hline \multicolumn{3}{|l|}{ Age at first parity (years) } \\
\hline$<18$ & $3 \cdot 4$ & 0.063 \\
\hline $19-24$ & $18 \cdot 2$ & \\
\hline$>25$ & $1 \cdot 7$ & \\
\hline \multicolumn{3}{|l|}{ Physiological status of mother } \\
\hline Pregnant & $4 \cdot 5$ & 0.043 \\
\hline Lactating & $44 \cdot 5$ & \\
\hline Non-lactating/non-pregnant & $4 \cdot 8$ & \\
\hline \multicolumn{3}{|l|}{ Maternal education } \\
\hline None & $49 \cdot 2$ & 0.03 \\
\hline Primary & $37 \cdot \overline{3}$ & \\
\hline Secondary & $8 \cdot 5$ & \\
\hline Tertiary & $5 \cdot 1$ & \\
\hline \multicolumn{3}{|l|}{ Distance to health facility $(\mathrm{h}$ ) } \\
\hline $0-0 \cdot 25$ & $10 \cdot 3$ & 0.06 \\
\hline $0.25-0.5$ & $5 \cdot 2$ & \\
\hline $0 \cdot 5-1$ & $19 \cdot 0$ & \\
\hline $1-2$ & $13 \cdot 8$ & \\
\hline$>2$ & $1 \cdot 7$ & \\
\hline
\end{tabular}

whose first complementary foods were composed of mostly cereal porridges were significantly $(P=0 \cdot 04)$ more anaemic than children those whose first complementary foods were animal products like cow's milk. The mothers' source of knowledge about Fe was not significantly associated with the anaemia status of their children.

\section{Factors associated with anaemia among mothers}

The results exploring the factors associated with anaemia status of the mothers are presented in Table 5 . The health status of the mother was highly associated $(P=0 \cdot 000)$ with her anaemia status, with mothers who had acute respiratory infections, worms or malaria being more anaemic. Mothers who were lactating were significantly $(P=0.043)$ more anaemic than non-lactating mothers. Maternal education was significantly $(P=0 \cdot 03)$ associated with the anaemia status of the mothers: almost half of the mothers (49.2\%) with no formal education and $37 \cdot 3 \%$ of mothers with only with primary level education were anaemic compared with $8 \cdot 5 \%$ and $5 \cdot 1 \%$ of mothers with secondary or tertiary education, respectively (Fig. 1). On the other hand, age of the mother, the age at which the mother had her first child (age of first parity) and distance to the health facility were not significantly associated with the anaemia status of the mother. 


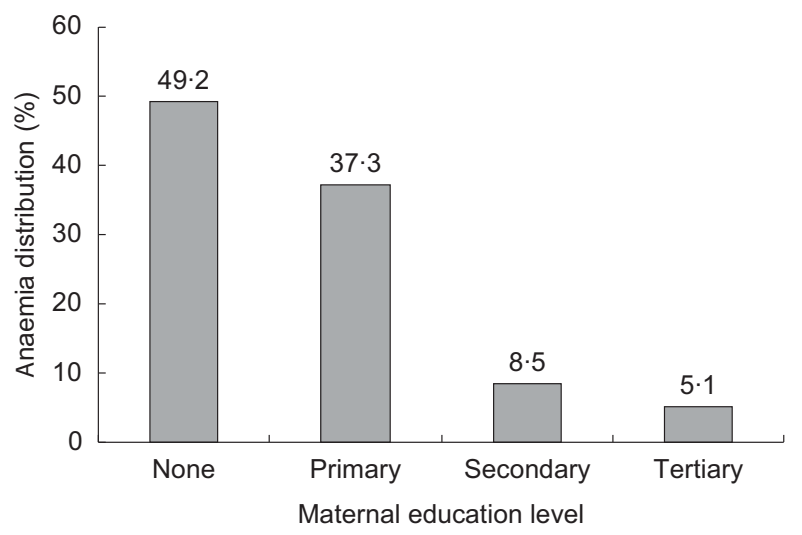

Fig. 1 Association of education with anaemia $(\mathrm{Hb}<11 \mathrm{~g} / \mathrm{dl})$ among mothers aged 15-49 years, Bushenyi district, rural Western Uganda

\section{Discussion}

\section{Gender and age of the child}

Some authors have found no significant difference in the prevalence of anaemia $^{(22)}$ or $\mathrm{Hb}$ concentration $^{(23)}$ in terms of gender, while others have demonstrated that the prevalence of anaemia can vary between male and female children $^{(23)}$. They argued that the higher prevalence among boys has to do with their growth; their bodies demand a higher amount of Fe, which cannot be supplied by the diet. The current study found that male children were significantly $(P=0 \cdot 005)$ more anaemic than female children in rural Western Uganda.

Among under-fives, those aged 6-24 months are at most risk of being Fe-deficient ${ }^{(24)}$. In the present study, children aged 13-24 months had significantly $(P=0 \cdot 019)$ higher levels of anaemia than those $<12$ months or $>24$ months of age. The Fe stores present at birth and in breast milk protect the infant from Fe deficiency up to 6 months of age ${ }^{(25)}$. However, breast milk alone cannot provide the Fe needs of an infant beyond 6 months of age. Above this age, dietary sources of Fe become critical to keep up with the child's rapid rate of red blood cell synthesis ${ }^{(26)}$.

\section{Factors related to complementary foods}

The choice of complementary foods markedly influences the Fe status of the child ${ }^{(27)}$. The first complementary foods given during infancy and early childhood pose a high risk factor for Fe deficiency if they are relatively low in $\mathrm{Fe}$ content. In the present study, children whose complementary foods were mostly made up of staples, e.g. cereal porridges, were significantly more anaemic $(P=0 \cdot 04)$ than children who were given animal products like cow's milk (Table 4).

Staple crops provide a large proportion of the total daily intake of energy and micronutrients among poor populations who have limited access to animal foods ${ }^{(28,29)}$. However, the sources of Fe from such foods are non-haem forms, which have low bioavailability ${ }^{(30,31)}$. The main problem with diets based on non-animal foods is that they usually contain large amounts of phytic acid, the most potent inhibitor of non-haem Fe absorption. Among the dietary factors involved in the causes of $\mathrm{Fe}$ deficiency, a low-Fe diet and low Fe bioavailability are some of the most important ${ }^{(32)}$.

The time of introduction of these complementary foods was significantly $(P=0 \cdot 001)$ associated with the anaemia status of the children in the current study. Most anaemic children $(88.3 \%)$ had complementary foods before 6 months of age. This period is associated with risk of infections, which are likely to cause childhood illnesses, especially diarrhoea. Information from other studies confirms that exclusive breast-feeding is protective against Fe deficiency for infants up to 6 months of age, after which the Fe concentration in breast milk will not meet the infant's Fe requirements ${ }^{(33)}$. When the infant receives exclusive breast-feeding, Fe stores from birth to the 6th month of life meet the infant's physiological requirements; therefore, infants do not have to be supplemented with other foods ${ }^{(34,35)}$ during this period owing to the high bioavailability of $\mathrm{Fe}$ in human milk (about 50\%), which can however decrease by $80 \%$ when infants are fed other foods. Therefore, early introduction of complementary foods is a risk factor for the development of Fe-deficiency anaemia in infants ${ }^{(36,37)}$. For children $>6$ months old, it has been reported that breast-feeding is not a predictive factor for Fe deficiency ${ }^{(38,39)}$.

Lack of special meals for the children was also significantly $(P=0 \cdot 028)$ associated with high levels of anaemia among the study children, as most anaemic children $(37 \cdot 1 \%)$ did not have any special meals prepared for them. The study results further showed that children with mothers who had no knowledge of enriching children's foods were significantly $(P=0.005)$ more anaemic compared with children whose mothers had knowledge on food enrichment. Traditional porridges, normally prepared by heating cereal flour with water, form an important part of the diet for weaning infants and young children. The starch granules bind much water, swell and gelatinize, becoming thick and viscous at very low concentrations, with high dietary bulk but low energy and nutrient density ${ }^{(40,41)}$. Use of a triple mixture of ingredients $^{(42)}$ and the addition of other nutrient-dense foods such as cow's milk and/or groundnuts ${ }^{(40)}$ would make them more nutrient-dense.

\section{Healtb factors}

A lack of appropriate health-care services that could prevent anaemia by enabling early identification of individuals with Fe deficiency does not allow the timely treatment of such condition. Therefore, health services should be in proximity to needy vulnerable groups, especially children and pregnant mothers. In relation to the above, children who were delivered at home were 
significantly $(P=0 \cdot 035)$ more anaemic compared with those delivered at health units (Table 4). This is because those mothers who delivered at health units had been getting antenatal care including Fe and folate supplementation.

Diseases and infections greatly lead to anaemia among pre-school children ${ }^{(42,43)}$ and pregnant women ${ }^{(43,44)}$ despite the number of intervention programmes to reduce the problem ${ }^{(21)}$. In the current study, the health status of the mother was highly associated $(P=0 \cdot 000)$ with her anaemia status, with mothers who had acute respiratory infections, worms and malaria being more anaemic. There are vast possibilities for developing anaemia after an acute infection episode, and these possibilities vary according to the length and severity of the disease ${ }^{(43,44)}$. According to Reeves et al $^{(45)}$, mild diarrhoeal disease affects approximately $60 \%$ of children aged $<1$ year, between the ninth and twelfth month of life, and these diseases are associated with low $\mathrm{Hb}$ concentration.

\section{Education and physiological status of the mother}

Mothers' education level was found to be a significant socio-economic factor for the occurrence of anaemia among both mothers $(P=0 \cdot 03)$ and their children $(P=0 \cdot 000)$, as shown in Fig. 1 . These findings are in agreement with those found in Uganda ${ }^{(12,13)}$ and elsewhere $^{(46)}$, and show that higher levels of undernutrition among the under-fives was related to lower maternal education.

In relation to physiological status of the mother, i.e. whether she is pregnant or lactating, it was observed that lactating mothers were more anaemic than non-pregnant/ non-lactating mothers and this agrees with the current findings in Uganda ${ }^{(12)}$. This could be attributed the fact that the mothers' Fe stores are being mobilized into milk for lactation.

\section{Relationship between Hb levels of motber and child}

In the present study, a positive and significant $(r=0.05$, $P=0.008)$ relationship was revealed between the anaemia status of the mother and the child. It was found that anaemic mothers had significantly more anaemic children. This is in agreement with the findings of other studies in Uganda $^{(12)}$.

\section{Conclusion}

Fe-deficiency anaemia was found to be a major problem in this cohort of children and their mothers. The most important factors that affected the $\mathrm{Hb}$ levels of the mothers and their children were place of birth, complementary foods (their type and time of introduction), age and sex of the child, and education, nutrition knowledge and physiological status of the mother.

The age at introduction of complementary foods was significantly $(P=0 \cdot 001)$ associated with the anaemia status of the children, with those who were introduced to complementary foods before 6 months of age having higher rates of anaemia (41.6\%) than those who started complementary foods after 6 months $(5 \cdot 0 \%)$. Most study children $(88.3 \%)$ had complementary foods before 6 months of age.

It is therefore recommended that rural mothers should be sensitized on best practices for proper child feeding and care in order to reduce the high prevalence of anaemia and associated health problems.

\section{Acknowledgements}

The study was supported by the Vision 2020 initiative of the International Food Policy Research Institute (IFPRI; Washington, DC, USA). The authors have no conflicts of interest. J.K.K. is the principal investigator; she wrote the project proposal and the study protocol, and supervised data collection, processing and write up. F.B.L. participated in data collection and assisted in writing the manuscript. F.T. participated in data collection and assisted in writing the manuscript. All authorities who granted us permission to carry out the study and everyone who gave us both material and moral support are gratefully acknowledged. We thank IFPRI for funding the study and the mothers and children who participated.

\section{References}

1. Allen L \& Gillespie S (2001) What Works? A Review of the Efficacy and Effectiveness of Nutrition Interventions. Geneva: UN ACC/SCN in collaboration with the Asian Development Bank.

2. Fishman S, Caulfield L, de Onis M, Blossner M, Hyder A, Mullany L \& Black R (2004) Childhood and maternal underweight. In Comparative Quantification of Health Risks: Global and Regional Burden of Disease Attributable to Selected Major Risk Factors, vol. 1, pp. 39-162 [M Ezzati, AD Lopez, A Rodgers and CJL Murray, editors]. Geneva: WHO.

3. Stoltzfus RJ, Chwaya HM, Tielsch JM, Schulze KJ, Albonico M \& Savioli L (1997) Epidemiology of iron deficiency anemia in Zanzibari schoolchildren: the importance of hookworms. Am J Clin Nutr 65, 153-159.

4. Sommer A \& West KP (1996) Vitamin A Deficiency: Health, Survival, and Vision. New York: Oxford University Press.

5. Stoltzfus RJ \& Dreyfuss ML (1998) Guidelines for the Use of Iron Supplements to Prevent and Treat Iron Deficiency Anemia. Washington, DC: ILSI Press.

6. Beard JL (2001) Iron biology in immune function, muscle metabolism and neuronal functioning. J Nutr 131, 2 Suppl. 2, S568-S579.

7. Karyadi D \& Bloem MW (1996) The role of vitamin A in iron deficiency anemia and implications for interventions. Biomed Environ Sci 9, 316-324.

8. Fleming AF (1981) Haematologic manifestations of malaria and other parasitic diseases. Clin Haematol 10, 983-1011.

9. van den Broek NR, White SA \& Neilson JP (1998) The association between asymptomatic HIV infection and the prevalence and severity of anemia in pregnant Malawian women. Am J Trop Med Hyg 59, 1004-1007. 
10. Administrative Committee on Coordination, Sub-committee on Nutrition (1987) First Report on the World Nutrition Status. Rome: FAO.

11. Grantham-McGregor SM \& Ani CC (1999) The role of micronutrients in psychomotor and cognitive development. Br Med Bull 55, 511-527.

12. Uganda Bureau of Statistics \& ORC Macro (2001) UDHS (Uganda Demographic and Health Survey), 2000-2001. Entebbe, Uganda/Calverton, MD: Uganda Bureau of Statistics \& and ORC Macro.

13. Uganda Bureau of Statistics\& ORC Macro (2006) UDHS (Uganda Demographic and Health Survey), 2006. Kampala, Uganda/Calverton, MD: Uganda Bureau of Statistics, and ORC Macro.

14. Sserunjogi L, Schult F \& Whyte SR (2003) Postnatal anaemia: neglected problems and missed opportunities in Uganda. Health Policy Plan 18, 225-231.

15. Ministry of Health, Republic of Uganda (2002) Anemia Policy. Kampala, Uganda: Ministry of Health.

16. Ministry of Health (1997) Burden of Disease Study. Kampala, Uganda: Ministry of Health.

17. Caulfield LE, Richard SA \& Black RE (2004) Undernutrition as an underlying cause of malaria morbidity and mortality in children. Am J Trop Med Hyg 71, Suppl. 2, S55-S63.

18. Ramakrishnan U, Aburto N, McCabe G \& Martorell R (2004) Multimicronutrient interventions but not vitamin A or iron interventions alone improve child growth: results from three meta-analyses. J Nutr 134, 2592-2602.

19. Stoltzfus RJ, Mullany L \& Black RE (2004) Iron deficiency anemia. In Comparative Quantification of Health Risks: Global and Regional Burden of Disease Attributable to Selected Major Risk Factors, vol. 1, pp. 163-209 [M Ezzati, AD Lopez, A Rodgers and CJL Murray, editors]. Geneva: WHO.

20. Uwaegbute AC (1991) Weaning foods and weaning practices of the Housas, Yorubas and Ibos of Nigeria. Ecol Food Nutr 26, 139-153.

21. World Health Organization/United Nations University/ UNICEF (2001) Iron Deficiency Anaemia Assessment, Prevention and Control: A Guide for Programme Managers. Geneva: WHO.

22. Michaelsen KF, Milman N \& Samuelson G (1995) A longitudinal study of iron status in healthy Danish infants: effects of early iron status, growth velocity and dietary factors. Acta Paediatr 84, 1034-1044.

23. Brault-Dubuc M, Nadeau M \& Dickie J (1983) Iron status of French-Canadian children: a three years follow-up study. Hum Nutr Appl Nutr 37A, 210-221.

24. ZIotkin S (2003) Clinical nutrition: the role of nutrition in the prevention of iron deficiency anemia in infants, children and adolescents. CMAJ 168, 59-63.

25. Dallman PR (2003) Changing iron needs from birth through adolescence. In Nutritional Anemias. Nestlé Nutrition Workshop Series no. 30, pp. 29-38 [SJ Fomon and SH Zlotkin, editors]. New York: Vevey/Raven Press.

26. Emond AM, Hawkins N, Pennock C \& Golding J (1996) Haemoglobin and ferritin concentrations in infants at 8 months of age. Arch Dis Child 74, 30-36.

27. Silva LSM, Giugliani ERJ \& Aerts DRGC (2001) Prevalence and determinants of anemia in Brazil. Rev Saude Publica 35, 66-73.

28. Allen LH, Backstrand JR, Chavez A \& Pelto GH (1992) Functional Implications of Malnutrition. People cannot live by tortillas alone: the results of Mexico CRSP. Final Report of Mexico Project. Washington, DC: Human Nutrition Collaborative Research Program, USAID.

29. Kikafunda JK, Walker AF \& Tumwine JK (2003) Weaning foods and practices in Central Uganda: a cross-sectional study. Afr J Food Agric Nutr Dev $\mathbf{2}$, issue 3.

30. Gibson RS (1994) Zinc nutrition in developing countries. Nutr Res Rev 7, 151-173.

31. Bouis H (1999) Enrichment of food staples through plant breeding: a new strategy for fighting micronutrient malnutrition. Nutr Rev 54, 131-137.

32. Yip R (1994) Iron deficiency: contemporary scientific issues and international programmatic approaches. J Nutr 124, 8 Suppl., 1479S-1490S.

33. Dallman PR, Siimes MA \& Stekel A (1980) Iron deficiency in infancy and childhood. Am J Clin Nutr 33, 86-118.

34. Siimes MA, Salmenpera L \& Perheentupa J (1984) Exclusive breastfeeding for 9 months: risk of iron deficiency. J Pediatr 104, 196-199.

35. Dewey KG, Cohen REJ, Rivera LL \& Brown KH (1998) Effects of age of introduction of complementary foods on iron status of breast-fed infants in Honduras. Am J Clin Nutr 67, 878-884.

36. Fairweather-Tait SJ (1992) Iron deficiency in infancy: easy to prevent - or is it? Eur J Clin Nutr 46, Suppl. 4, S9-S14.

37. Lönnerdal B (1984) Iron and breast milk. In Iron Nutrition and Infancy and Childhood. Nestlé Nutrition Workshop Series no. 4, pp. 95-117 [A Stekel, editor]. New York: Raven Press.

38. Karr M, Alperstain G, Cuser JC \& Mira M (1996) Iron status and anaemia in preschool children in Sydney. Aust $N Z J$ Public Health 20, 618-622.

39. Lehmann F, Gray-Donald K, Mongeon M \& Tommaso SD (1992) Iron deficiency anemia in one year old children of disadvantaged families in Montreal. CMAJ 146, 1571-1577.

40. Kikafunda JK, Walker AF \& Abeyasekera S (1997) Optimising viscosity and energy density of maize porridges for child weaning in developing countries. Int J Food Sci Nutr 48, 401-409.

41. Gompakis N, Economou M, Tsantali C, Kouloulias V, Keramida M \& Athanasiou-Metaxa M (2007) The effect of dietary habits and socioeconomic status on the prevalence of iron deficiency in children of northern Greece. Acta Haematol 117, 200-204.

42. World Health Organization/UNICEF (1998) Complementary Feeding of Young Children in Developing Countries: A Review of Current Scientific Knowledge. WHO/NUT/98.1. Geneva: WHO.

43. Jansson LT, Kling S \& Dallman PR (1986) Anemia in children with acute infections seen in a primary care pediatric outpatient clinic. Pediatr Infect Dis 4, 424-427.

44. Osório MM, Lira PIC \& Batista-Filho M (2001) Prevalence of anaemia in children 6-59 months old in the state of Pernambuco, Brazil. Rev Panam Salud Publica 10, 101-107.

45. Reeves JD, Yip R, Kiley VA \& Dallman PR (1984) Iron deficiency in infants: the influence of mild antecedent infection. J Pediatr 105, 874-879.

46. Brooker S, Peshu N, Warn PA, Mosobo M, Guyatt HL, Marsh K \& Snow RW (1999) The epidemiology of hookworm infection and its contribution to anemia among preschool children on the Kenyan coast. Trans $R$ Soc Trop Med Hyg 93, 240-246. 